\title{
MISÉRIA, INFÂNCIA E AFROBRASILIDADE: OS REFLEXOS DE UMA CONSTRUÇÃO NACIONAL ASSIMÉTRICA RETRATADOS NA LITERATURA DE CONCEIÇÃO EVARISTO
}

\author{
MISERY, CHILDHOOD AND AFRO-BRAZILIANNESS: \\ REFLECTIONS OF AN ASYMMETRIC \\ NATIONAL CONSTRUCTION DEPICTED \\ IN CONCEIÇÃO EVARISTO'S LITERATURE
}

\author{
Sara Regina de Oliveira Lima ${ }^{1}$ \\ Universidade Estadual do Piauí \\ Maria Aline Porto Brito² \\ Universidade Estadual do Piauí
}

\begin{abstract}
Resumo: Este artigo tem por objetivo analisar as relações de miséria e infância nos contos "Zaíta esqueceu de guardar os brinquedos" e "Lumbiá" de Conceição Evaristo (2015), destacando as condições das crianças negras em situação de vulnerabilidade social a partir de uma literatura crítica, representativa e de resistência. Por ser uma pesquisa bibliográfica de caráter exploratório, baseia-se nos estudos empreendidos por Duarte (2010), Evaristo (2009), Engels (2010), Priore (2010), Santos (2017), dentre outros. Para mais, é possível observar que, ao ocupar, em grande parte, a margem da sociedade, crianças negras encontram-se cada vez mais distanciadas do suporte da família e do Estado, construindo suas vivências com base na violência, no trabalho infantil, bem como na negação dos seus direitos como mostra os contos analisados.
\end{abstract}

Palavras-Chave: Miséria; Infância; Crianças negras; Literatura.

1 Endereço eletrônico: sararegina@prp.uespi.br.

2 Endereço eletrônico: alineporto12@hotmail.com. 
Abstract: This article aims to analyze the relations of misery and childhood in "Zaita esqueceu de guardar os brinquedos" and "Lumbiá", short stories by Conceição Evaristo (2015), highlighting the black children's situation of social vulnerability through a critical and representative literature. As an exploratory bibliographic research, it is based on studies caried by Duarte (2010), Evaristo (2009), Engels (2010), Priore (2010), Santos (2017), among others. Furthermore, it is possible to observe that by occupying largely the margin of society, black children are increasingly cut off from the support of the family and the State, thus, building their experiences on the basis of violence, child labor, as well as, in the denial of their rights as the analyzed short stories show.

Keywords: Misery; Childhood; Black children; Literature.

\section{INTRODUÇÃO}

Ao dispor de um caráter fundamentalmente representativo, a literatura afrodescendente organiza-se como recorte de uma expressão da identidade negra brasileira ao tratar das vivências nas quais encontram-se, por muitas vezes, omitidas pelo padrão branco burguês, em que este dedica-se a um posicionamento de discursos que apagam a memória do povo negro, negando sua identidade e seu desenvolvimento progressivo, vindo a produzir, desse modo, roteiros limitados sob forma de impor a permanência do negro na margem social de forma contínua. Ao considerar esta escrita, o desejo pela desconstrução de uma visão estereotipada do povo negro, assim como pela busca da visibilidade e da quebra de barreiras diante da sociedade e da literatura brasileira instiga-nos a esta pesquisa, dado que,

colocar a questão colonial significa ter em conta que a representação problemática da diferença cultural e racial não pode ser simplesmente lida a partir dos sinais e desenhos da autoridade social que se produzem nas análises de diferenciação [...]. (BHABHA, 1992, p. 177)

Nessa percepção, considera-se, em conformidade com Duarte (2010), que a literatura afrodescendente é, em sua totalidade, discursividade, em que nesse processo ela posiciona-se em alinhamento à cor da pele, assumindo, assim, o papel de importante instrumento diante de uma tradução textual, tanto de uma 
história própria, quanto coletiva. A exemplo dessa literatura de resistência, destaca-se aqui Conceição Evaristo que apresenta uma escrita composta a partir do diálogo com as vivências diárias dos grupos excluídos, caracterizando-se, assim, como uma espécie de testemunho real-ficcional, conforme aponta Oliveira (2015).

Ao emitir ecos de luta e crítica por meio de suas autorias, expondo todas as dores vivenciadas pelo povo negro, Conceição Evaristo, sendo mulher de intensa herança africana, na tentativa de uma ressignificação, bem como valorização do negro, permite que seus leitores mergulhem de maneira profunda em sua escrita a partir do momento em que a ficção apresenta-se unificada a uma realidade que clama por mudanças de direito e igualdade. Dessa forma, a autora aborda e expõe a dura realidade vivenciada pela comunidade afro-brasileira por meio de sua tessitura poética fortemente explícita, possibilitando, a partir de suas obras, que seu público leitor venha a despertar uma ampla criticidade, desenvolvendo questionamentos e traçando todos os paralelos existentes entre passado e presente.

Uma vez vista como produtora de resistência, a literatura afrodescendente configura-se também como produto em que Conceição Evaristo, ocupando posição não somente de escritora, mas também de pesquisadora, considera que:

tendo sido o corpo negro, durante séculos, violado em sua integridade física, interditado em seu espaço individual e coletivo pelo sistema escravocrata do passado e, ainda hoje, pelos modos de relações raciais que vigoram em nossa sociedade, coube aos brasileiros, descendentes de africanos, inventarem formas de resistência que marcaram profundamente a nação brasileira. (EVARISTO, 2009, p. 18)

Em face de toda a vulnerabilidade e contrariedade vivenciada diariamente pelo povo negro, que se encontra desmascarada na literatura de Conceição Evaristo, observa-se uma relação da infância com o modelo de vida proposto dentro das favelas e/ou comunidades cercadas pela miséria. Esta, por sua vez, 
conecta copiosos destinos de uma sociedade largamente distanciada de oportunidades e direitos, compreendendo um problema no qual a "diversidade temática situa-se na história contemporânea e busca trazer ao leitor os dramas vividos na modernidade brasileira, com suas ilhas de prosperidade cercadas de miséria e exclusão" (DUARTE, 2010, p. 123). Em vista disso, ao apresentar a figura infantil em seus contos, a autora compromete-se a descrever, por meio da literatura, a criança na condição de sujeito desprovido dos direitos que envolvem seu desenvolvimento saudável, expondo a realidade de forma visível, e demonstrando, dessa forma, toda a sua crítica.

Para mais, nesta temática, todas as situações que caracterizam a negação do ser criança encontram-se evidenciadas, uma vez que, de acordo com Santos e Silva (2018), ao concentrar os olhares em crianças pertencentes à classe baixa, levando em consideração uma visão que centralize tanto classe, quanto raça, observa-se a grandeza do desnivelamento apresentado, dado que a sociedade busca adotar idealizações absolutamente incompatíveis com a realidade, mostrando, dessa forma, o quanto a infância encontra-se sujeita à difusão de ideias distorcidas. Destarte, é possível perceber todas as disparidades verificadas em um grupo de crianças que vive na miséria, sobretudo crianças negras, compondo, desse modo, os mais diversos espaços.

Por consequência, origina-se um ciclo vicioso que se mantém de forma intensa, percorrendo incessantemente todo o caminho de formação, bem como de construção subjetiva do sujeito enquanto criança negra. Dessa forma, a falta de equidade e a irregularidade vivenciada por estas crianças acarretam em implicações, também, na sua vida adulta, quando estas não possuem a vida interrompida ainda na infância, visto que suas vivências encontram-se dispostas em uma constante de risco entre vida e morte. Sendo estas crianças cercadas pela miséria, observa-se que o contexto de pobreza vivenciado abrange e evidencia uma sucessão de perigos já manifestos, em que estes encontram-se relacionados 
ao presente e, dessa forma, refletem no futuro, resultando em um processo totalmente indesejável ao desenvolvimento infantil, conforme assegura Crestani e Rocha (2018).

Posto isto, ao contrariar as noções de infância perfeita e buscar elementos constituintes de dada assimetria social na literatura, esta pesquisa materializa-se na concepção da infância negra brasileira ao tratar da sua coexistência com a miséria e a sua negação destinada ao viver, dado que "[...] a criança, assim como o adulto, é definida como um sujeito que se constitui na história e na cultura e, simultaneamente, também produz culturas" (FERRARINI; QUEIROZ; SALGADO, 2016, p. 1033). Desse modo, ao constituir-se por intermédio de fatores objetivos nos quais lideram a subjetividade infantil, a condição histórica e social das crianças negras pode ser amplamente verificada nos contos Zaíta esqueceu de guardar os brinquedos e Lumbiá, ambos presentes no livro Olhos d'água (2015), de Conceição Evaristo, desenvolvendo, assim, um estudo acerca da relação da sociedade com a literatura afrodescendente, em que essa escrita feminina negra dialoga com todo um grupo de excluídos por meio de um viés crítico e reflexivo.

\section{A CONSTRUÇÃO DA SUBJETIVIDADE INFANTIL NA SOCIEDADE BRASILEIRA: NEGAÇÃO DE ESPAÇOS E INTERROMPER DE VIVÊNCIAS}

Constituída por elementos históricos e sociais, a infância passou a ser difundida a partir de lacunas impostas pela sociedade. Durante o período no qual instaurava-se a colonização no país, as crianças vieram a transitar por um elevado processo de desumanização, sendo estas consideradas apenas como elo para geração de riquezas em substituição aos adultos. Suas mortes precoces correspondentes às condições de existência oferecidas a elas não eram consideradas para além de apenas menos um, sem maiores comoções. Assim, 
conforme discorre Mauad (2010, p. 75), apenas “o século XIX ratifica a descoberta humanista da especificidade da infância e da adolescência como idades da vida", traduzindo, em vista disso, a criança como ser social.

A partir de então, permite-se observar o avanço destinado à proteção da criança no Brasil, dado que, a ideia de infância e até mesmo os valores atribuídos à criança na sociedade não possuíram seu ponto de partida ancorados nos conceitos hoje discursados, ainda que estes apresentem falhas, contradições e as mais diversas e elevadas formas de exclusão. Em conformidade com as leis destinadas às crianças brasileiras, é permissível deduzir, seguramente, que por instituir-se como ser social detentor de direitos, estas crianças possuem toda a assistência necessária para seu desenvolvimento digno. De forma incompatível, percebe-se que grande parcela dessas crianças não possui sua existência destinada a dados planos formais. A título de exemplo, observam-se as personagens exibidas no fazer artístico de Evaristo (2015) como representações de existências em constante aviltamento.

Atualmente, os discursos aplicados para a elucidação da criança estão na infância como fase plena, à qual possui assistência direcionada a todas estas que estão em situação de vulnerabilidade social ao suprir suas necessidades primeiras enquanto indivíduo. Ao considerar os planos do Estatuto da Criança e do Adolescente, Lei nº 8.069, de 13 de Julho de 1990, o art. $7^{0}$ atesta que: “a criança e o adolescente têm direito a proteção à vida e à saúde, mediante a efetivação de políticas sociais públicas que permitam o nascimento e o desenvolvimento sadio e harmonioso, em condições dignas de existência" (BRASIL, 1990). Contudo, nos contos em questão, estes direitos são subtraídos juntamente com a integridade das crianças abordadas por Conceição Evaristo, quando estas encontram-se de frente com a fome, a violência, o trabalho infantil, a corrupção, o preconceito racial, a maldade e a morte. 
Sendo a infância de grande parte das crianças negras extensivamente firmada na miséria, observa-se que a estrutura familiar daquele que é constituído a partir das marcas da pobreza terá seu desenvolvimento fortemente comprometido. Em Zaíta esqueceu de guardar os brinquedos, ao tomar conta do conflito vivenciado no conto - o sumiço de uma figurinha imensamente adorada pela menina Zaíta, supostamente pega pela sua irmã gêmea, Naíta, que tanto tencionava a figurinha para si - verifica-se a inquietude da pequena menina ao bagunçar todos os singelos brinquedos, sob forma de procurar, em silêncio, pela sua estimada figurinha, visto que, caso o conflito interno da menina viesse a materializar-se aos olhos da mãe, aconteceria o esperado: "a mãe ficaria com raiva e bateria nas duas. [...] Batia nas meninas, reclamava do barraco pequeno, da vida pobre, dos filhos, principalmente do segundo" (EVARISTO, 2015, p. 7172).

Em vista disso, considera-se que as preocupações da mãe de Zaíta, advindas da pobreza e do seu estado de exaustão, proporcionava uma série de efeitos nos quais acometia o desejo de partilha dos pequenos problemas da menina, bem como determinado pedido de ajuda direcionado à mãe. Desse modo, conforme aponta Santos (2017, p. 59), apresentando-se de forma degradante, “a pobreza é condição objetiva que, na sua face mais perversa, imprime nítidas marcas tanto na estrutura psíquica dos indivíduos, quanto na sua estrutura física tornando o corpo do miserável testemunho do seu flagelo". Assim, é possível observar que Zaíta optava por comportar-se em estado inerte quando o assunto tratava-se das suas angústias internas, deixando traços em seu desenvolvimento psicológico, além da sua relação com a própria mãe, conturbada pelo excesso de miséria presente em seu núcleo familiar.

Durante a narrativa, Evaristo (2015) expõe os anseios dos irmãos das pequenas gêmeas. Já adultos, ambos queriam seguir carreira, mas de forma diferenciada. Um encontrava-se em formação no Exército, já o outro preferia 
passear por caminhos incertos e perigosos. Este, por sua vez, "via os seus trabalharem e acumularem miséria no dia a dia. [...] via mulheres, homens e até mesmo crianças, ainda meio adormecidos, saírem para o trabalho e voltarem pobres como foram, acumulados de cansaço apenas" (EVARISTO, 2015, p. 73$74)$.

A partir dos seus questionamentos, o irmão da menina reconhece de forma precisa o sistema de reprodução de miséria por ele vivenciado. Ao fazer parte de uma sociedade regida pelo capitalismo, o jovem não se mostra confortável diante de um trabalho que venha a caracterizar-se como exploratório. Dessa maneira, assim como pontua Santos (2017, p. 49), "na sociabilidade do capital o trabalho deixa de ser visto como intercâmbio entre homem e natureza e produtor do ser social para se tornar trabalho exteriorizado, produtor de mais-valia". Para tal concepção, considera-se a educação, aliada ao Estado, como fator preponderante para a concentração de riqueza entre as classes dominantes, em que esta passa a gerir a distinção entre ricos e pobres, de acordo com os modelos de educação Reprodutora e Neoliberal, pontuados por Fogaça e Gimenez (2007).

De modo contínuo, encontra-se uma formação de qualidade diretamente voltada aos que possuem concentração de riqueza, sendo esta, de preferência e em sua maioria, composta por brancos, visando, desse modo, a preparação para o comando. No entanto, por outro lado, obtém-se a educação direcionada à população de classes baixas, compostas em sua maioria por negros, carentes de oportunidades, ficando à mercê de um trabalho escravizador mascarado ao constituir o quadro de manutenção da elite através da sua produção.

Para mais, tal pensamento manifesto pelo jovem estruturou-se a partir da sua infância, dado que,

desde pequeno, ele vinha acumulando experiências. Novo, criança ainda, a mãe nem desconfiava e ele já traçava o seu caminho. Corria ágil pelos becos, colhia recados, entregava encomendas, e displicentemente assobiava uma 
música infantil, som indicativo de que os homens estavam chegando. (EVARISTO, 2015, p. 74)

O crescimento no cerne da miséria conceitua-se, muitas vezes, como força motriz para a busca de caminhos considerados mais rápidos. Ao possuir sua infância devastada pelo tráfico entre os becos da favela, muitas crianças, como aponta Silva e Urani (2002), constituem-se de características nas quais podem ser consideradas comuns entre si. Entre tais aspectos, destaca-se o pertencimento às famílias que partilham de uma pobreza fortemente ativa no núcleo das favelas, sendo estas crianças, em maior parte, negras ou pardas, com sua escolaridade extremamente inferior se comparada à média brasileira, considerada por volta dos 6,4 anos.

Desse modo, desde antes de completarem 12 anos de idade, ao almejar uma mudança de vida no que se refere às suas condições de miséria, estas crianças perdem-se no âmbito da criminalidade, bem como da violência, dado que, sem perspectiva de crescimento e assistência para um desenvolvimento saudável, o espaço no qual convivem mostra, cotidianamente, os dois caminhos a serem seguidos em seu percurso de vida, tal como a sua liberdade de escolha. Ao considerar a educação, assim como a assistência de crianças em seu compromisso com a elevação social do indivíduo, é possível questionar o seu real lugar no meio social, uma vez que esta, por vezes, apresenta-se ineficiente diante da estruturação da miséria. No entanto, sabe-se que esta é uma ferramenta substancial para reverter tais fatos à vista da elevada desigualdade presente na esfera social.

Ao tratar das condições de miséria presentes em seu íntimo familiar, Benícia - mãe de Zaíta - reflete sobre suas condições de existência. Esta, por sua vez, é fielmente observada, em tal intensidade, como elemento constituinte da realidade das famílias brasileiras negras e periféricas, sendo elas próprias utilizadas como ferramenta principal para a reprodução da sua pobreza. Desse 
modo, é possível observar as angústias vivenciadas pela personagem no seguinte trecho:

a mãe de Zaíta guardou rapidamente os poucos mantimentos. Teve a sensação de ter perdido algum dinheiro no supermercado. Impossível, levara a metade do salário e não conseguira comprar quase nada. Estava cansada, mas tinha de aumentar o ganho. Ia arranjar trabalho para os finais de semana. [...] Havia também o aluguel, a taxa de água e de luz. Havia ainda a irmã com os filhos pequenos e com o homem que ganhava tão pouco. [...] Estava, porém, chegando à conclusão de que trabalho como o dela não resolvia nada. Mas o que fazer? Se parasse, a fome viria mais rápida e voraz ainda. (EVARISTO, 2015, p. 74-75)

Em vista disso, a partir do sistema de reprodução do capital, a violência econômica, podendo ser encarada como estabelecida com base no Estado, apresenta-se como fator preponderante no núcleo familiar a partir da exploração da classe trabalhadora, que extrapola seus limites diante da sociedade de classes, garantindo, assim, a elevação das classes dominantes de forma excessiva. Para tanto, tais explorações, quando vivenciadas por mães e/ou pais de família, exibem suas implicações no desenvolvimento das crianças existentes em dado grupo.

Conforme destaca Engels (2010), o trabalho, principalmente aquele vinculado à conduta feminina, ao caracterizar-se como exploratório, com jornadas excessivamente fatigantes e desenvolvidas em um período de doze a treze horas por dia, constitui-se como elemento propulsor para uma ruptura no círculo familiar. Além disso, com o homem também distante do convívio das crianças, ficando a cargo da obrigatoriedade no desenvolvimento de atividades que sustentam suas vivências de forma desvalida, os corpos infantis prosseguem suas vidas sem cuidados e sem garantia de proteção, passando por uma variedade de descuidos. Desse modo, a partir da ausência de um responsável resultante do trabalho excessivo - as crianças constituem-se cada vez mais como vítimas diante da falta de atenção e dos devidos cuidados que, por sua vez, 
deveriam ser concretizados perante a responsabilidade destinada ao amparo da infância.

No conto, a partir do tratamento destinado às pequenas gêmeas, bem como aos seus irmãos, que já vieram a passar por tal situação no constituir das suas respectivas infâncias, se justifica as implicações destinadas ao desenvolvimento da criança na sociedade. Os questionamentos postos pelos seus pais ou responsáveis surgem como guisa de tortura entre uma escolha que irá gerar custos: o trabalho exploratório com os filhos à mercê dos becos das ruas, vielas e favelas, ou a fome batendo à porta e invadindo casas compostas por indivíduos que projetam em suas vidas apenas uma oportunidade de sobrevivência digna.

Como criança que fora esquecida pela mãe ao mergulhar em suas reflexões advindas da miséria, Evaristo (2015) desenha sua narrativa ao trâmite final de forma simbólica. Assim, a mãe das pequenas meninas, ao desprender-se dos seus próprios pensamentos e retornar rapidamente para as ações vivenciadas no momento, começa a destruir a boneca negra, dado que a sua representação real, Zaíta, vinha a ter sua vida destruída brutalmente logo em seguida. Nota-se, no trecho a seguir, a primeira ação aqui pontuada:

Apanhou a boneca negra, a mais bonitinha, a que só faltava um braço, e arrancou o outro, depois a cabeça e as pernas. Em poucos minutos, a boneca estava destruída; cabelos arrancados e olhos vazados. [...] e de raiva ela havia arrebentado aquela bonequinha negra, a mais linda. (EVARISTO, 2015, p. 7576)

Ao construir, no decorrer da narrativa, a semelhança da personagem Zaíta com a boneca negra, observa-se as ações efetuadas por Benícia como características de uma violência intrafamiliar. Considerando a preocupação materna com o filho envolvido no tráfico, aliada aos demais fatores, a mãe da 
menina Zaíta desenvolve uma espécie de fuga de emoções a partir do tratamento destinado às gêmeas. Desse modo, no seio familiar,

as crianças são as maiores vítimas, pois a raiva, os ressentimentos, as impaciências e as emoções negativas dos outros membros as atingem como se elas fossem uma válvula de escape. [...] a violência intrafamiliar contra crianças e adolescentes costuma ser funcional, provocando uma espécie de homeostase. Sua fragilidade física e de personalidade as tornam alvos fáceis do poder dos adultos. (LIMA, 2006, p. 33)

Evaristo (2015) ergue os fatos da narrativa com direção a uma poeticidade do real intenso e impetuoso. Ao tratar da violência presente na favela, composta em parte por um grupo liderado pelo próprio irmão da pequena Zaíta, a autora exibe as cenas de violência, tiros, ameaças ao viver, cortes de vidas de formas brutais e a disputa de poder. Simultaneamente, observa-se a tentativa do não abandono da infância, ainda que este aconteça de forma precoce:

o barulho seco de balas se misturava à algazarra infantil. As crianças obedeciam à recomendação de não brincarem longe de casa, mas às vezes se distraíam. E, então, não experimentavam somente as balas adocicadas, suaves, que derretiam na boca, mas ainda aquelas que lhes dissolviam a vida. (EVARISTO, 2015, p. 76)

A busca pela liberdade de ser criança em um contexto dominado pela violência, procedente da busca de liderança em meio às misérias, transforma o singelo ato de brincar na rua em medo acompanhado de olhares vigilantes, sob tentativa de proteger sua própria vida e de seus pequenos colegas. Dessa forma, a ausência de espaços dignos à atividade lúdica na comunidade apresenta-se como forma de exposição direta aos perigos. Para tanto, o cessar da brincadeira por apenas alguns minutos pode tornar-se em um nunca mais diante da realidade social.

Considera-se, portanto, que a violência presenciada e vivenciada pelas crianças possui sua efetivação nos mais diversos meios, desde a própria casa, 
estendendo-se pelas ruas, instituições, escolas, e para além destes espaços. Suas consequências, quando não destinadas à morte, expandem-se em angústias psicológicas e emocionais a longo prazo, vindo a danificar o seu desenvolvimento íntegro, como por exemplo nas suas relações com e na sociedade, o desenvolvimento dos seus processos de aquisição, além do sistema de reprodução da violência na vida adulta, visto que, quando criança, muitas vezes as imagens de violência são captadas e entendidas como a única forma destinada à solução de problemas.

Ao dar seguimento ao seu objetivo, Zaíta encontra-se defronte a uma dessas situações de violência com a presença de tiroteios, comumente enfrentada por todos aqueles que residem na favela. Observa-se, desse modo, a seguinte passagem:

Zaíta seguia distraída em sua preocupação. Mais um tiroteio começava. Uma criança, antes de fechar violentamente a janela, fez um sinal para que ela entrasse rápido em um barraco qualquer. [...] Ela procurava, entretanto, somente a sua figurinha-flor... Em meio ao tiroteio a menina ia. Balas, balas e balas desabrochavam como flores malditas, ervas daninhas suspensas no ar. Algumas fizeram círculos no corpo da menina. Daí a um minuto, tudo acabou. Homens armados sumiram pelos becos silenciosos, cegos e mudos. Cinco ou seis corpos, como o de Zaíta, jaziam no chão. (EVARISTO, 2015, p. 76)

Nota-se que as instruções em defesa da vida seguiam nítidas, mas a menina Zaíta desejava apenas o resgate da sua figurinha-flor, de uma memória doce, característica do ser criança. Ao término de tamanha improbidade, ela estava morta. A menina transformara-se em pequena flor destruída, representando vidas de milhares de crianças que um dia também possuíram suas existências devastadas, e infelizmente a sociedade continua experienciando tais situações de forma alarmante.

Destarte, corroborando com Lima (2006), é possível destacar a existência de perfis característicos das vítimas na sociedade brasileira, dado que suas 
mortes podem ser consideradas a partir de termos socioculturais, como escolaridade, residir em periferias, encontrar-se gravado no ciclo da pobreza, ser negro ou, ainda, possuir alguma descendência. Assim, pode-se afirmar, que apesar da violência encontrar-se presente em toda a extensão, sua distribuição não é democrática. Esta, por seu turno, sempre recairá sobre as camadas que possuem sua estrutura econômica frágil, composta em maior evidência por negros. Para mais, ao fim da narrativa, Evaristo (2015) demonstra a inocência de Naíta aliada a uma cena de dramaticidade, na qual acontece o encontro tão esperado por Zaíta, em que, nessa ocasião, consumou-se tarde demais. Dessa forma, verifica-se tal descrição:

A outra menina seguia aflita à procura da irmã para lhe falar da figurinhaflor desaparecida. Como falar também da bonequinha negra destruída? Os moradores do beco onde havia acontecido o tiroteio ignoravam os outros corpos e recolhiam só o da menina. Naíta demorou um pouco para entender o que havia acontecido. E, assim que se aproximou da irmã, gritou entre o desespero, a dor, o espanto e o medo: - Zaíta, você esqueceu de guardar os brinquedos! (EVARISTO, 2015, p. 76)

Naíta encontrava-se em busca da irmã e de como falar da figurinha, da boneca linda, negra, destruída. Outrossim, a menina negra também estava em situação semelhante à boneca: Zaíta teve sua vida devastada por completo. Já Naíta, teve seu psicológico abalado, presenciou o corpo da irmã sendo retirado do caos então estabelecido e, possivelmente, não contará com qualquer suporte para se desvencilhar do luto despertado, visto que a pobreza detém continuidade em seu âmbito familiar. Mas o recado consistia em um só: a mãe estava cansada da vida constituída pela pobreza, estava brava e, logo naquele dia, Zaíta esquecera de guardar os brinquedos.

A partir de uma poeticidade estritamente lapidada pelo real, observa-se agora a infância presente em Lumbiá. No conto, o menino Lumbiá, juntamente com sua irmã Beba e o colega Gunga, apresentam-se como figuras atuantes no 
trabalho infantil a partir da venda de chicletes, amendoim e flores, carregando consigo marcas de uma infância negada, fruto da miséria instalada em suas vivências:

Lumbiá trocou rapidamente a lata de amendoim pela caixa de chicletes com a irmã Beba. Fazia um bom tempo que estava andando para lá e para cá, e não havia conseguido vender nada. Quem sabe teria mais sorte se oferecesse chicletes? E, se não desse certo também, procuraria o colega Gunga. Juntos poderiam vender flores. A mãe não gostava daquela espécie de mercadoria. Dizia que flor encalhada era prejuízo certo. [...] Lumbiá gostava da florida mercadoria em seus braços. Tinha até um estilo próprio de venda. (EVARISTO, 2015, p. 81)

Ao adotar seu estilo de venda, observa-se que o pequeno menino possui apenas um objetivo: levar o dinheiro arrecadado a partir da simples mercadoria e entregá-lo à mãe, sob forma de garantir o próprio sustento, bem como o da sua família. Para mais, conforme o art. 60ํ do Estatuto da Criança e do Adolescente ${ }^{3}$ : “é proibido qualquer trabalho a menores de quatorze anos de idade, salvo na condição de aprendiz" (BRASIL, 1990). Longe disso, o trabalho infantil, presente no contexto da pobreza vivenciada pelo povo negro manifesta-se como ramificação do passado. Assim, conforme aponta Santos (2010), com a escravidão dada por encerrada, o século XX instituiu-se marcado pelo crescimento populacional, urbanização e industrialização das cidades, junto à tentativa do povo negro de se estabelecer na sociedade, bem como a sua exclusão. Por sua vez, estes não eram mais denominados de escravos, mas todos os traços que compunham o período mostravam-se fincados no corpo social da época, e para além dela, em que estes podem ser verificados nitidamente na sociedade corrente.

Com a falta de oportunidades de trabalho digno, moradia, educação, saúde, ou seja, assistência para as famílias negras cercadas pela miséria, as

3 Lei no 8.069, de 13 de Julho de 1990. 
crianças viram-se obrigadas a ajudar suas famílias em busca de sobrevivência. Seja pelo trabalho infantil, introduzido, em maior parte, pelas fábricas e oficinas em suas atividades de produção, ou ainda pelo roubo, mendicância e prostituição, por exemplo, a ilegalidade fazia-se ocultada. Desse modo, não importava a atividade a ser exercida, visto que as necessidades oriundas da pobreza ecoavam incessantemente. Em vista disso, observa-se a formação de trajetos destinados à um sistema de retrocesso voltado aos desfavorecidos, vindo a contradizer um país que ditava progresso, fortalecido pelo capital industrial.

Assim, ao apresentar-se de forma cada vez mais crescente, a pobreza evidente no íntimo das famílias gerou uma excessiva multiplicação de crianças nas ruas e no interior das indústrias, em que as condições de trabalho inadequadas eram neutralizadas diante das necessidades finais dos pequenos trabalhadores. Ao contrário do que se esperava do novo período, o bem-estar das classes populares encontrava-se gradualmente perdido diante de uma sociedade descompromissada com grande parte da população. Desse modo, as crianças provenientes de um núcleo familiar carente estavam cada vez mais sujeitas aos fatores que, por sua vez, destruíam a infância, como o trabalho, a violência, a fome, a criminalidade, a falta de educação, saúde, cultura, lazer ou até mesmo o abandono dos pais, somente para citar alguns.

Atualmente, constituindo-se como violência estrutural, o trabalho infantil ainda pode ser observado a níveis máximos de exploração da infância brasileira. Ao relacionar-se diretamente com a educação proposta a essas crianças, tendo o Estado como fio condutor para a promoção somente das classes dominantes, verifica-se, em decorrência do trabalho, o distanciamento entre criança e escola. Conforme salienta Rizzini (2010, p. 209), “os filhos dos mais pobres trocam a escola pelo trabalho", haja vista que as excessivas jornadas fomentam o esgotamento do ser infantil. Em seguimento, obtém-se a caracterização destas crianças a partir da "má escolarização, negação de tempo para atividades lúdicas, 
além de sequelas nutricionais, envelhecimento precoce, desenvolvimento comprometido e ainda, em alguns casos, estímulo à corrupção e prostituição" (LIMA, 2006, p. 42), ocultando, desse modo, toda a estruturação e desenvolvimento do ser criança.

As emoções do menino Lumbiá, advindas do bloqueio da infância, podem ser observadas a partir da materialização posta durante a narrativa, na qual a autora descreve:

Lumbiá tinha ainda outros truques. Sabia chorar, quando queria. Escolhia uma mesa qualquer, sentava, abaixava a cabeça e se banhava em lágrimas. Sempre começava chorando por safadeza, mas, em meio às lágrimas ensaiadas, o choro real, profundo, magoado se confundia. Nas histórias, que inventava nos momentos de choro para comover as pessoas, tinha sempre uma dissimulada verdade. [...] E, enquanto chorava o pranto ensaiado para comover os compradores, contava ora sobre a surra que havia levado da mãe, ora sobre a mercadoria que estava ficando encalhada (e ele precisava retornar para casa com um bom resultado de venda), ou, ainda, sobre o dinheiro, fruto de seu trabalho, que tinha sido tomado por um menino maior... E aos poucos, em meio às verdades-mentiras que tinha inventado, Lumbiá ia se descobrindo realmente triste, tão triste, profundamente magoado, atormentado em seu peito-coração menino. (EVARISTO, 2015, p. 83)

Desse modo, ao possuir suas vivências a partir das relações sociais complexas, o menino possui seu quadro emocional fragilizado, no qual configura-se, por vezes, em ilusões mascaradas, resultado real da vida laboriosa. No conto, ele encontra o esvaziamento parcial dos sentimentos dolorosos diante de uma estratégia de venda, vindo a amenizar, desse modo, o sofrimento pelo próprio sofrimento. Ademais, os sentimentos infantis ocultados e transformados em angústia podem desenvolver na criança sérios danos à sua saúde mental, haja vista a ausência de amparo para com elas. As dificuldades presentes em suas vidas podem ser encaradas como passaporte de fácil acesso ao desenvolvimento da depressão e da ansiedade, por exemplo, custando-lhes caro a capacidade de 
relacionar-se efetivamente na sociedade, bem como a sua edificação enquanto indivíduo.

Ao apresentar o único elemento reflexo de felicidade para o personagem, a contista exibe as marcas da simplicidade presente no ser infantil. Observa-se o seguinte trecho:

Havia, porém, uma ocasião em que nada ameaçava os dias gozosos do menino: o advento do Natal. [...] Dos presentes expostos nas vitrines, principalmente os embrulhados, tinha vontade de apanhá-los e amassá-los. Ficava irritado, sabia que tudo eram caixas vazias. Só havia uma coisa de que o menino gostava no Natal. Um único signo: o presépio com a imagem de Deus-menino. Todos os anos, desde pequeno, em suas andanças pela cidade com a mãe e mais tarde sozinho, buscava de loja em loja, de igreja em igreja, a cena natalina. Gostava da família, da pobreza de todos, parecia a sua. Da imagem-mulher que era a mãe, da imagem-homem que era o pai. A casinha simples e a caminha de palha do Deus-menino, pobre; só faltava ser negro como ele. Lumbiá ficava extasiado olhando o presépio, buscando e encontrando o Deus-menino. (EVARISTO, 2015, p. 83-84)

A partir da caraterização da sua infância, Lumbiá destitui do seu imaginário o Natal como aquele que volta-se, em sua maior parte, à figura do Papai Noel e dos presentes, muitas vezes cheios do material, mas esvaziados de sentimentos. Como criança distanciada destes elementos, o pequeno menino consegue identificar a significação real da data na qual marca o nascimento de Jesus, reconhecendo sua semelhança com a cena do presépio, tem retratado a imagem do seu ser a partir da pobreza, dado que a identificação a partir do outro sempre se fez de maneira inválida diante do povo negro.

Desse modo, observam-se as raízes desse desnivelamento de identificação presente durante o período escravocrata, visto que as crianças negras partilhavam dos mesmos espaços nos quais as crianças brancas eram criadas, em que as primeiras serviam como uma espécie de brinquedo dentro de casa. Por sua vez, ao atingir sete anos de idade os filhos dos senhores eram introduzidos na educação escolar, enquanto que as crianças negras iam trabalhar. Assim, 
durante o seu crescimento, ao coabitar apenas com pessoas brancas e detentoras de riquezas, as crianças negras escravas prontamente conceituavam o trabalho e a pobreza como algo já preestabelecido, diferentemente da educação.

Em vista disso, a dificuldade de encontrar, em sua totalidade, uma fonte de identificação na qual venha a elevar o pensamento de que o negro possui espaço na sociedade e configure a sua existência em lugares de prestígio apresenta-se, ainda, em níveis máximos. Por este motivo, Lumbiá associa a pobreza e o corpo negro como elementos que deveriam estar em conjunto, ao passo que, ao identificar-se com a imagem de Jesus, o pequeno menino analisa a ausência de um dos elementos característicos da sua semelhança. Assim, a personagem apresenta-se como retrato de múltiplas crianças negras e vulneráveis tanto socialmente, quanto economicamente, em que seus imaginários são perpassados por conceituações findadas a partir de uma sociedade preconceituosa, base para a reprodução da desigualdade a partir da negação de espaços.

Em continuidade, o protagonista encontra-se diante de uma barreira instalada entre ele e o menino Jesus. Ele deseja contemplar um belo presépio situado no interior de uma loja, limitado à entrada de crianças sem a presença de algum responsável. A partir da consciência de que sua mãe não estaria disposta a acompanhá-lo, exibindo a ausência dela em seu desenvolvimento no decorrer de toda a narrativa, Lumbiá tenta entrar na loja diversas vezes, sob forma de observar a cena do presépio com toda a sua ternura, em que tais tentativas efetuam-se sem sucesso. No entanto, o menino não se dá por vencido:

O dia caminhava para seis da tarde, vinte e três de dezembro. O menino aguardava ali desde as nove da manhã. Em sua viagem costumeira do subúrbio para o centro da cidade, se distanciou de Gunga e da irmã. Tinha flores nas mãos, rosas amarelas. Havia combinado com o amigo que venderiam flores, mas aquelas ele daria para o Menino Jesus e também poria algumas nas mãos do Rei Baltasar. Fazia frio, muito frio, era um dia chuvoso. Tinha a roupa colada sobre o frágil corpo a tremer de febre. [...] O Casarão 
Iluminado abrira naquele dia só para visitação pública ao presépio. Precisava chegar até lá. Como? Já tinha feito várias tentativas, sendo sempre expulso pelo segurança. Ia arriscar novamente. Em dado momento aproximou-se devagar. Ninguém na porta. Mordeu os lábios, pisou leve e, apressado, entrou. (EVARISTO, 2015, p. 85)

Desse modo, destaca-se, ainda, o trajeto feito pelo pequeno menino, bem como as suas condições de saúde. Para mais, tais elementos fazem parte da rotina de inúmeras crianças, em que morando, por exemplo, nas favelas, possuem a necessidade de deslocamento para os grandes centros. Em busca de algum dinheiro para um sustento escasso, estas possuem seu estado de saúde ignorado, haja vista que este dificilmente é amparado, bem como todos os elementos constituintes do ser vulnerável. Assim, por conviverem constantemente com a falta de assistência tanto da família, quanto do Estado, essas crianças possuem seu desenvolvimento pleno degradado, opondo-se, desse modo, ao que é posto nos planos legais.

Ao conseguir entrar na loja, diante da imagem do menino Jesus no presépio, Lumbiá exterioriza uma fusão de sentimentos entre a alegria, a dor, a busca de semelhança e identidade. Desse modo, o pequeno menino atinge o ápice das suas emoções, no qual configura-se o seu encontro com a imagem de Jesus, bem como o corte brutal da sua vida:

Lá estava o Deus-menino de braços abertos. $\mathrm{Nu}$, pobre, vazio e friorento como ele. Nem as luzes da loja, nem as falsas estrelas conseguiam esconder a sua pobreza e solidão. Lumbiá olhava. De braços abertos, o Deus-menino pedia por ele. Erê queria sair dali. Estava nu, sentia frio. Lumbiá tocou na imagem, à sua semelhança. Deus-menino, Deus-menino! Tomou-a rapidamente em seus braços. Chorava e ria. Era seu. Saiu da loja levando o Deus-menino. $\mathrm{O}$ segurança voltou. Tentou agarrar Lumbiá. O menino escorregou ágil, pulando na rua. O sinal! O carro! Lumbiá! Pivete! Criança! Erê, Jesus Menino. Amassados, massacrados, quebrados! Deus-menino, Lumbiá morreu! (EVARISTO, 2015, p. 85-86) 
Diante de todo o seu sofrimento, Lumbiá sente o real significado da pobreza e grandeza vivenciada por ele e refletida na imagem de Jesus no presépio. A simplicidade e inocência do ser criança faz com que o menino efetue o resgate do menino Jesus. No que lhe diz respeito, esta apresenta-se como a atitude esperada pelo menino a partir da sociedade: ser resgatado de uma pobreza ríspida e perversa.

Ademais, diante da negação de espaço, Lumbiá rompe as barreiras que o impediam naquele momento, dado que este achava-se distante da figura da mãe como acompanhante, além de ser mal visto, ainda, pela pobreza aparente e pela cor da sua pele. Na tentativa da sua fuga com a imagem do menino Jesus, suscitando, assim, em sua morte, o garoto encontra-se em face de uma violência social, em que, conforme aponta Lima (2006, p. 24), “crianças e adolescentes pobres são mais vulneráveis e expostos aos acidentes e violências e aos danos por estes provocados", uma vez que encontram-se cotidianamente nas ruas.

Com a sua vida dada por encerrada, representa uma quantidade infindável de crianças negras e constituídas pela pobreza a partir das mais variadas manifestações de desigualdade. Lumbiá não possuiu condições de vida digna, oportunidade de educação e desenvolvimento, pois conforme aponta Priore (2010), mesmo com o passar dos séculos, o desenvolvimento social das crianças segue firmado na violência, seja ela tanto explícita, quanto implícita, deixando a educação em segundo plano, em que "a formação moral e intelectual, bem como os códigos de sociabilidade, raramente aproximam as crianças de conceitos como civilidade e cidadania" (PRIORE, 2010, p. 57), assegurando, desse modo, um infindável ciclo de desigualdades. 


\section{CONSIDERAÇÕES FINAIS}

Nos contos apresentados sob objeto de análise, Zaíta e Lumbiá representam, de forma direta, a realidade de diversas crianças na sociedade, marcada pelo passado e estruturada em um ciclo vicioso de desigualdades. São corpos existentes e resistentes, protagonistas da vida em sua instância máxima, frutificados no seio de uma sociedade de classes, na qual antefere o bem comum apenas entre a classe dominante. Desse modo, a partir das narrativas levantadas por Evaristo (2015), é possível observar a dimensão da literatura afrodescendente, a qual permite ao leitor viajar por espaços ocultados, constituídos de uma realidade dolorosa e efêmera da ficção.

A relação existente entre criança negra, pobreza e educação descreve os detalhes da acumulação do capital baseada em uma violência econômica e posta a partir de variadas faces, em que essas crianças se encontram cada vez mais exploradas e violentadas. Sem acesso à educação, em decorrência, na maioria das vezes, da miséria já instalada em suas vivências, observa-se o distanciamento entre criança e escola, que se traduz em desigualdades sociais e educacionais, bem como em ausência de oportunidades.

Distante da educação e a partir das suas necessidades, as crianças vulneráveis destinam-se ao trabalho sem levar em consideração a inversão de papéis em um futuro próximo, em que, sem qualificação, estas acabam cedendo espaços aos adultos brancos, firmando, desse modo, a real estratégia formulada nas entrelinhas do poder. De fato, é bem verdade que, mesmo em uma sociedade em constante evolução, observa-se a educação como desviada da formalidade e legalidade acentuada e proferida em discursos extensos e deturpados. Outrossim, observam-se todas as ramificações da pobreza existentes no íntimo das crianças negras e periféricas a partir dos mais diversos conflitos existentes 
em seu espaço de convívio, levando em consideração, ainda, o seu próprio lar, conforme visto nos contos trabalhados.

Assim, considera-se que o seguimento da pobreza efetua-se como consequência de tradições perpetuadas ao longo da história a partir da subalternização dos indivíduos que, outrora, já pertenciam às classes detentoras da miséria. A construção da infância no corpo social, sobretudo da infância negra, fortemente abordada nos contos, estrutura-se na falta de assistência e educação, com seu desenvolvimento constituído ao lado da violência, do medo, da opressão, da falta do apoio familiar, em que todos estes fatores, juntamente com as condições de vulnerabilidade social, formam-se como conjunto preponderante ao ápice da miséria. Ademais, a solidão presente no íntimo dessas vivências configura-se, ainda, como elemento fortemente presente na subjetividade das crianças em vulnerabilidade, desenvolvendo na criança danos prolongados à sua vida.

Desse modo, a literatura apresentada por Evaristo (2015) traduz de forma efetiva a realidade da infância brasileira baseada na miséria e ocultada pela sociedade. Diante dos contos trabalhados, é possível observar a relação da criança cercada pelo pauperismo com a rua, que se configura como espaço de negação e, ao mesmo tempo, de resgate, o qual representa tanto o amor, quanto o refúgio e a dor. Destaca-se, ainda, a construção dos personagens dentro das narrativas, que, mesmo possuindo suas singularidades, conversam entre si a partir das situações de angústia evidenciadas pela pobreza, constituindo-se como vítimas da mesma. Além disso, nos contos, a simbologia efetuada pela autora remete a delicadeza da flor análoga ao ser infante, na qual desperta a inocência da tentativa de ser em si, assim como o seu desenvolvimento a florir, cortado pela sua raiz na configuração das suas mortes, resultado de uma sociedade que busca interromper a vida de milhares de crianças. Para além, quando a morte destas crianças não se materializa no corpo em si, manifesta-se a partir do roubo da 
infância em sua essência, tornando-as, desse modo, em pequenos adultos forçados em meio ao sofrimento. Tratam-se, desse modo, de corpos, sonhos, direitos, vidas e subjetividades, todos entrecortados.

Para mais, reitera-se, neste estudo, o reconhecimento de todos os pontos positivos ao tratamento destinado às crianças no desenvolver das sociedades. Contudo, tais pontos não possuem o poder de ocultar as desigualdades e simular uma sociedade preparada para a descaracterização futura do que é separação entre classe e raça da maneira como apresenta-se atualmente. Desse modo, a urgência de transformação apresenta-se de forma nítida e necessária a partir de um sistema que priorize o nivelamento social, bem como a igualdade racial, baseada, em sua gênese, na educação, elemento primordial para o progresso, se efetuada de forma justa e correta. Destarte, sustenta-se, ainda, a importância da literatura afrodescendente como arte de resistir, representar e denunciar, sendo, assim, elemento indispensável para a formação crítica entre literatura e sociedade.

\section{REFERÊNCIAS}

BHABHA, Homi k. "A questão do "outro": diferença, discriminação e o discurso do colonialismo". In: HOLLANDA, H. B. Pós-modernismo e política. Rio de Janeiro: Rocco, 1992. p. 177-203.

BRASIL. Lei no 8.069, de 13 de julho de 1990. Dispõe sobre o Estatuto da Criança e do Adolescente e dá outras providências. Diário Oficial [da] República Federativa do Brasil, Brasília, DF, 16 jul. 1990. Disponível em:

[http://www.planalto.gov.br/ccivil_03/LEIS/L8069.htm\#art266] Acesso em: 03/02/ 2021. CRESTANI, Vanessa; ROCHA, Kátia Bones. Risco, vulnerabilidade e o confinamento da infância pobre. Psicologia e Sociedade, v. 30, e177502. 2018.

DUARTE, Eduardo de Assis. Por um conceito de literatura afro-brasileira. Terceira Margem. Rio de Janeiro, v.14, n. 23, p. 113-138. 2010.

ENGELS, Friedrich. A situação da classe trabalhadora na Inglaterra. Tradução por Schumann, B. A. São Paulo: Boitempo, 2010.

EVARISTO, Conceição. Literatura negra: uma poética de nossa afro-brasilidade. Scripta. Belo Horizonte, v. 13, n. 25, p. 17-31, 2ํㅗ. 2009. 
EVARISTO, Conceição. Olhos d'água. 1. Ed. Rio de Janeiro: Pallas: Fundação Biblioteca Nacional, 2015.

FERRARINI, A. R. K.; QUEIROZ, F. R. O.; SALGADO, R. G. Infância e Escola: tempos e espaços de crianças. Educação \& Realidade. Porto Alegre, v. 41, n. 4, p. 1027-1048. 2016.

FOGAÇA, F. C.; GIMENEZ, T. N. O Ensino de Língua Estrangeira e a Sociedade. Revista Brasileira de Linguística Aplicada. Belo Horizonte, v. 7, n. 1, p.161-182. 2007.

LIMA, Cláudia Araújo de. Violência faz mal à saúde. Brasília: Ministério da Saúde, 2006.

MAUAD, Ana Maria. A vida das crianças de elite durante o império. In: PRIORE, M. D. História das crianças no brasil. 7. ed. São Paulo: Contexto, 2010. p. 74-95.

OLIVEIRA, Margarete Aparecida de. Narrativas de favela e identidades negras: Carolina Maria de Jesus e Conceição Evaristo. 2015. 115 f. Dissertação. (Mestrado em Estudos Literários: Teoria da Literatura e Literatura Comparada) Faculdade de Letras, Universidade Federal de Minas Gerais, Belo Horizonte.

PRIORE, Mary Del. O cotidiano da criança livre no brasil entre a colônia e o império. In: PRIORE, M. D. História das crianças no brasil. 7. ed. São Paulo: Contexto, 2010. p. 47-58.

RIZZINI, Irma. Pequenos trabalhadores do brasil. In: PRIORE, M. D. História das crianças no brasil. 7. ed. São Paulo: Contexto, 2010. p. 207-222.

SANTOS, Marco Antonio Cabral dos. Criança e criminalidade no início do século xx. In: PRIORE, M. D. História das crianças no brasil. 7. ed. São Paulo: Contexto, 2010. p. 117-128.

SANTOS, Maria Escolástica de Moura. A educação social e a gestão da pobreza: gênese, desdobramentos e função no contexto da sociabilidade do capital em crise. 2017. $237 \mathrm{f}$. Tese. (Doutorado em Educação) Federal do Ceará, Faculdade de Educação Universidade, Fortaleza.

SANTOS, Marinilda Gomes dos; SILVA, Patrícia Maria da. A construção da infância na literatura brasileira: Jônatas Conceição e Conceição Evaristo, reflexões sobre novas formas de reexistência e representações da infância negra. Revista da $A B P N$, v. 10, Ed. Especial - Caderno Temático: Letramentos de Reexistência, janeiro de 2018, p. 794-810.

SILVA, J. S; URANI, A. Crianças no narcotráfico: um diagnóstico rápido. Organização Internacional do Trabalho: Ministério do Trabalho e Emprego. - Brasília: OIT, 2002.

Nota do editor:

Artigo submetido para avaliação em: 30 de março de 2021.

Aprovado em sistema duplo cego em: 27 de setembro de 2021. 